\title{
Mössbauer Studies of Narrow Fractions of Fly Ash Formed after Combustion of Ekibastuz Coal
}

\author{
Mikhail Vereshchak ${ }^{1}$ (D), Irina Manakova ${ }^{1, *}$, Adilkhan Shokanov $^{2}$ and Sayabek Sakhiyev $^{3}$ (D) \\ 1 Institute of Nuclear Physics, Ibragimov st. 1, Almaty 050032, Kazakhstan; mikhail.vereshchak@mail.ru \\ 2 Institute of Mathematics, Physics and Informatics, Abai Kazakh National Pedagogical University, \\ Dostyk Av. 13, Almaty 050010, Kazakhstan; adilhan.shokanov@mail.ru \\ 3 Kazakh National Agrarian Research University, Abai Av. 8, Almaty 050010, Kazakhstan; ssayabek@yandex.ru \\ * Correspondence: i.manakova25@mail.ru; Tel.: +7-777-172-1672
}

check for updates

Citation: Vereshchak, M.; Manakova,

I.; Shokanov, A.; Sakhiyev, S.

Mössbauer Studies of Narrow Fractions of Fly Ash Formed after Combustion of Ekibastuz Coal. Materials 2021, 14, 7473. https:// doi.org/10.3390/ma14237473

Academic Editor: Israel Felner

Received: 21 October 2021

Accepted: 2 December 2021

Published: 6 December 2021

Publisher's Note: MDPI stays neutral with regard to jurisdictional claims in published maps and institutional affiliations.

Copyright: (C) 2021 by the authors. Licensee MDPI, Basel, Switzerland. This article is an open access article distributed under the terms and conditions of the Creative Commons Attribution (CC BY) license (https:/ / creativecommons.org/licenses/by/ $4.0 /)$.

\begin{abstract}
Nuclear gamma-resonance spectroscopy on ${ }^{57} \mathrm{Fe}$ nuclei, $\mathrm{X}$-ray diffraction, and scanning electron microscopy have been used to study the narrow fractions of fly ash formed after combustion of the Ekibastuz coal. Two groups of samples of magnetic (ferrospheres) and non-magnetic type have been separated by granulometric and magnetic separation. A number of regularities associated with the granules size of fly ash have been established. According to the data of Mössbauer spectroscopy, a decrease in the magnetically ordered contribution has been identified with the growth of the particle size. After magnetic separation, iron in ferrospheres was found mainly in the structure of $\mathrm{Fe}_{3} \mathrm{O}_{4} / \gamma-\mathrm{Fe}_{2} \mathrm{O}_{3}$ and $\alpha-\mathrm{Fe}_{2} \mathrm{O}_{3}$. The dominant phase was $\mathrm{Fe}_{3} \mathrm{O}_{4}(60-77 \%)$, the amount of which decreases with the growth of the grain size. With the growth of the particle size, the ratio of $[\mathrm{Fe}]^{\text {tetra }} /[\mathrm{Fe}]^{\text {octa }}$ positions occupancy in $\mathrm{Fe}_{3} \mathrm{O}_{4}$ approaches 0.5 ; the structure of magnetite tends to the stoichiometric composition. $\alpha$-Fe was found in the composition of ferrospheres, and a mechanism of its formation was proposed. The main components of the non-magnetic fractions of fly ash are mullite, hercynite, and silicate glass.
\end{abstract}

Keywords: Mössbauer spectroscopy; fly ash; granulometric and magnetic separation

\section{Introduction}

Kazakhstan is a country with huge hydrocarbon reserves, and it occupies the 10th place in the world in terms of solid fuel reserves. The main source of fuel for thermal power plants (TPP) is the Ekibastuz coal basin, where coal is mined by the open method, which makes this type of solid fuel the cheapest, but it is characterized by a high ash content of $\approx 50 \%[1,2]$. Therefore, a huge amount of the ash and slag mixture has been accumulated in the ash dumps of Kazakhstan, which creates a great threat to the environment [2-4]. It should be noted that with a sufficiently high level of the ash-slag waste production, only a small percentage of it is recycled. This leads to a rapid accumulation of waste from industrial coal combustion. In turn, it forces us to search for the ways of waste processing into valuable materials. The problems of ash-slag waste disposal in Russia, China, and Kazakhstan, where Ekibastuz coal is significant in the thermal power complex, were discussed in the works [3-8].

Currently, the ash-slag wastes are widely used in the construction industry $[4,8,9]$ and road construction $[10,11]$. Ferrospheres and aluminosilicate microspheres in fly ashes are formed as a result of thermochemical and phase transformations during coal combustion [4,12-14]. Ferrospheres are the perspective materials for the development of catalysts for the reactions of oxidation of methane condensation and sorbents of liquid radioactive waste $[12,13]$. The most peculiar and valuable components of ash are cenospheres. They are hollow aluminosilicate balls of almost ideal shape with a smooth surface, from 10 to several hundred $\mu \mathrm{m}$ in diameter. Wall thickness is from 0.2 to $10 \mu \mathrm{m}, \mathrm{T}_{\text {melt }}=1400-1500{ }^{\circ} \mathrm{C}$, density is $580-690 \mathrm{~kg} \cdot \mathrm{m}^{-3}$ [15-17]. The unique properties of cenospheres have led to a 
wide range of their application in the production of lightweight heat-insulating materials, radio-transparent ceramics, lightweight mixtures, etc. There are a number of factors affecting the formation of microspheres with different microstructures. The most important of them are the types of boilers and combustion conditions. So, in the paper [6], significant differences were established in the phase composition of fly ashes as well as their components, depending on the heat-power characteristics of the boilers.

Many papers have been devoted to the study of fly ashes. It is shown in $[4,6,7,10,13,18]$ that the main magnetic components of fly ashes are magnetite $\mathrm{Fe}_{3} \mathrm{O}_{4}$ and hematite $\alpha-\mathrm{Fe}_{2} \mathrm{O}_{3}$. In addition, the presence of $\gamma-\mathrm{Fe}_{2} \mathrm{O}_{3}$ in fly ash was discovered in [6,7]. Fly ashes contain the paramagnetic components as mullite $[19,20]$ and hercynite $[6,20]$, as well as silicate glasses and various calcium silicates with the impurities of iron $[7,20]$. However, in contrast to $[6,20]$, the presence of hercynite in fly ash was not found in $[18,19]$. Despite the fairly extensive research, the interpretation of the physical-chemical properties of fly ashes is still required. This work includes a detailed study of the narrow fractions of fly ashes subjected to separate granulometric and magnetic separation. Nuclear gammaresonance spectroscopy (Mössbauer effect) is used as the main method of research. This method, equipped with a modern mathematical instrument, is the most informative (and in some cases the only one) for identifying the iron-containing phases. The Mössbauer core serves as probe in a solid state. It can be used to study the dynamic properties; structural, valence, and charge states of the Mössbauer atom; the phase composition; and the atomic, crystalline, magnetic, and electronic features of the structure of the studied substance [21-28]. Separation into magnetic and non-magnetic components makes it possible to facilitate the analysis of the chemical and phase state of iron in individual fractions of fly ashes, which is enriched by separation [15].

\section{Materials and Methods}

Fly ash from a pulverized combustion of coal in the Ekibastuz basin in the boiler unit furnace BKZ-420-140 KA2 (Barnaul Boiler Plant, Barnaul, Russia) of TPP-2 in Almaty at a flame temperature of $1500-1900{ }^{\circ} \mathrm{C}$ was used as an initial product to obtain the narrow fractions. The ash was collected on the electrostatic filter. The particle size ranged from 0.2 to $500 \mu \mathrm{m}$. From the analysis of the literature data [1,5,29], it follows that the average particle size of fly ash is usually $50-100 \mu \mathrm{m}$. Taking this fact into account, the separation of narrow fractions of microspheres was carried out by the standard sieves with the mesh size of 25,40 , and $100 \mu \mathrm{m}$. Four series of samples were prepared in this way. The results of granulometric separation are shown in Table 1. Furthermore, magnetic separation of each of the obtained fractions was completed in two stages. At the first stage, a barium oxide magnet (ferroalloy $\mathrm{BaOFe}_{12} \mathrm{O}_{18}$ ) was used, creating a field strength of 700 Oe. This enabled us to separate non-magnetic parts in a pure form from the fractions produced by granulometric separation. At the second stage, the remaining magnetic parts of the fractions were subjected to more thorough separation using a permanent magnet with a low field strength of $\approx 50$ Oe. So, if usually ferrospheres in fly ash are from 3 to $17 \mathrm{wt} \%$ [4], then by dry and wet magnetic separation, the content of magnetic concentrate can be increased to $95 \mathrm{wt} \%$ or more [15]. This method enabled us to separate the ferrospheres with high iron content and estimate the amount of paramagnetic impurity, which is mechanically bound (apparently sintered) with the magnetic part of the separated samples. Thus, two groups of the narrow fraction samples have been prepared: magnetic and non-magnetic types.

Table 1. Content of narrow fractions in fly ash after granulometric separation.

\begin{tabular}{cc}
\hline Particle Size, $\boldsymbol{\mu m}$ & Content, wt $\%$ \\
\hline$<25$ & 7.60 \\
$25 \div 40$ & 17.27 \\
$40 \div 100$ & 36.80 \\
$>100$ & 38.33 \\
\hline
\end{tabular}


The chemical state of iron in the crystal structure of fly ash narrow fractions was determined by Mössbauer spectroscopy (MS) at ${ }^{57} \mathrm{Fe}$ nuclei. The spectra were recorded in transmission geometry on a MS-1104Em spectrometer (Research Institute of Southern Federal University, Rostov-on-Don, Russia) at room temperature. ${ }^{57} \mathrm{Co}$ in a chromium matrix served as a source of $\gamma$-quanta. The Mössbauer spectra were processed using the software SpectrRelax (Version 2.4, Lomonosov Moscow State University, Moscow, Russia) [30]. $X$-ray diffraction (XRD) and scanning electron microscopy (SEM) were used as additional methods. The X-ray spectra were measured on a diffractometer Bruker D8 ADVANCE (Karlsruhe, Germany) with a Cu-K $\mathrm{K}_{\alpha}$ emitter in the Bragg-Brentano geometry. The card files ASTM and TCPDS were used to identify the crystalline phases. The morphology and elemental composition of fly ash narrow fractions was studied using a scanning electron microscope JEOL JSM-06610 (Tokyo, Japan) equipped with the IncaX-act energy dispersive analyzer with a resolution of $3 \mathrm{~nm}$ at accelerating voltage of $0.3-30 \mathrm{kV}$ and accumulation time of $10 \mathrm{~min}$. The elemental composition was recalculated for oxides; the amount was brought to $100 \%$.

\section{Results and Discussion}

Figure 1 shows the Mössbauer spectra of the sample of Ekibastuz coal. As can be seen, the main component of the coal spectrum is the doublet belonging to $\mathrm{Fe}^{2+}$ in the crystal structure of siderite $\mathrm{FeCO}_{3}$. In addition to siderite, coal contains $\mathrm{Fe}^{3+}$ in the structure of pyrite $\mathrm{FeS}_{2}(13 \pm 1 \%$ of total spectrum). Thus, pyrite and siderite are the main precursors in the formation of ferrospheres during coal combustion. The mineral part of the Ekibastuz coal also contains clay minerals of the composition of kaolinite $\mathrm{Al}_{2} \mathrm{Si}_{2} \mathrm{O}_{3}(\mathrm{OH})_{4}$, quartz $\alpha-\mathrm{SiO}_{2}$, and carbonate $\mathrm{CaCO}_{3}$ [12]. In [31,32], magnetite was found as an impurity in coal, but the traces of this mineral were not found in this work.

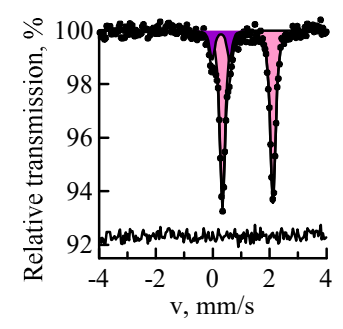

Figure 1. MS spectra of ${ }^{57} \mathrm{Fe}$ nuclei of the Ekibastuz coal sample: siderite (pink); pyrite (purple).

Figure 2 shows the Mössbauer spectrum of the sample of fly ash after the combustion of Ekibastuz coal and restored distributions of hyperfine magnetic field $p\left(H_{n}\right)$. As can be seen, the ash composition differs significantly from the original mineral components due to their significant changes under the influence of high temperatures. At the temperature of $585^{\circ} \mathrm{C}$, siderite, the content of which is $\approx 10 \%$ in the Ekibastuz coal [12], decomposes with the release of carbon dioxide $\mathrm{CO}_{2}$ and the formation of iron and its oxides, depending on the partial pressure of $\mathrm{O}_{2}, \mathrm{CO}$, and $\mathrm{CO}_{2}$. Pyrite also decomposes with the subsequent oxidation of iron [6]. According to the data of chemical analysis, the main components of ash and slag are $\mathrm{SiO}(45-60 \%), \mathrm{Al}_{2} \mathrm{O}_{3}(15-25 \%), \mathrm{Fe}_{2} \mathrm{O}_{3}(5-15 \%), \mathrm{CaO}(1.5-4.5 \%)$, and $\mathrm{K}_{2} \mathrm{O}$ $(2.0-4.5 \%)$ [1].

As can be seen, the experimental Mössbauer spectrum of the fly ash is characterized by a rather complicated structure. The iron atoms occupy several positions in magnetically ordered and paramagnetic states. The spectrum cannot be described by a small discrete set of partial spectra. Therefore, for processing of the experimental data, distributions of hyperfine parameters were applied in the evaluation of the Mössbauer spectra [30]. The relative $X^{2}$ was $1.17 \pm 0.06$.

Table 2 shows the Mössbauer parameters of the magnetic part of the MS spectrum of fly ash. The magnetic part of the spectrum consists of five sextets. The sextet $S 1$ is characterized by the parameters inherent to hematite $\alpha-\mathrm{Fe}_{2} \mathrm{O}_{3}$. The sextet $S 2$ is defined by $\mathrm{Fe}^{3+}$ ions in the 
tetrahedral position of $\mathrm{Fe}_{3} \mathrm{O}_{4}$. The sextet $\mathrm{S} 3$ corresponds to $\mathrm{Fe}^{3+}$ ions, and the sextets $\mathrm{S} 4-\mathrm{S} 5$ correspond to $\mathrm{Fe}^{2+}$ ions in the octahedral position of $\mathrm{Fe}_{3} \mathrm{O}_{4}$. The presence of two types of sextets $S 3$ and $S 4-S 5$ is associated with the significant non-stoichiometry of magnetite. As it is known, the ratio of tetrahedral position occupancy to octahedral position occupancy is $[\mathrm{Fe}]^{\mathrm{tetra}} /[\mathrm{Fe}]^{0 \mathrm{cta} a}=0.5$ for stoichiometric magnetite [33]. Electronic exchange is disturbed in case of non-stoichiometric magnetite $\mathrm{Fe}_{3} \mathrm{O}_{4}$. The sextet from $\mathrm{Fe}$ in the octahedral position decomposes into several non-equivalent states, and the Mössbauer spectrum gets a rather complex structure. In the literature, the spectrum of non-stoichiometric magnetite is often decomposed into three sextets: $\mathrm{Fe}^{3+}$ in the tetrahedral position, and $\mathrm{Fe}^{3+}$ and $\mathrm{Fe}^{2+}$ in the octahedral position. However, in practice, the picture is much more complicated, which is associated with the conditions of magnetite formation. The ratio $[\mathrm{Fe}]^{\text {tetra }} /[\mathrm{Fe}]^{\text {octa }}$ is disturbed. The reasons for this disturbance are either isomorphic impurities in the octahedral position of $\mathrm{Fe}_{3} \mathrm{O}_{4}$, or the admixture of maghemite (and/or other impurities with close Mössbauer parameters) to magnetite. The isomorphic capacity of $\mathrm{Fe}_{3} \mathrm{O}_{4}$ is largely a function of temperature. At high temperatures, magnetite is able to capture the impurities of a number of elements [6]. In the present experiment, $[\mathrm{Fe}]^{\text {tetra }} /[\mathrm{Fe}]^{0 \mathrm{cta} a}=0.72$.
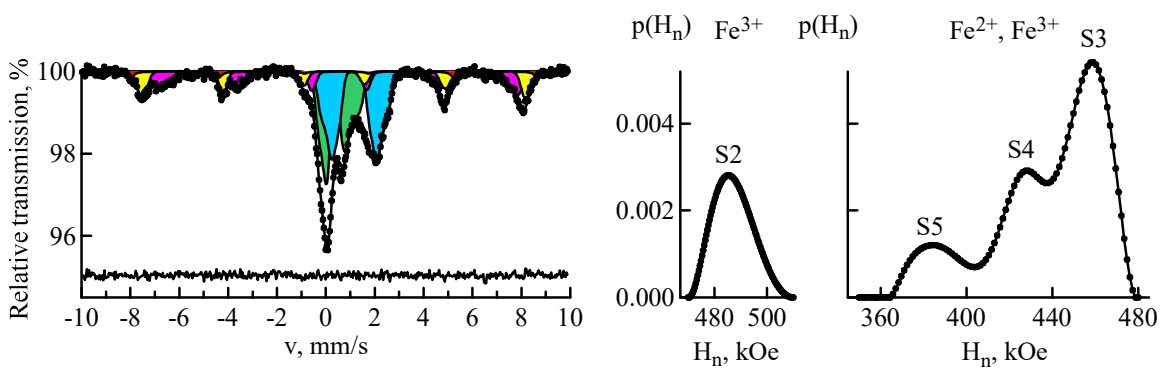

Figure 2. MS spectrum of ${ }^{57} \mathrm{Fe}$ nuclei of the fly ash sample and restored distributions of hyperfine magnetic field $p\left(H_{n}\right)$ : hematite (red); magnetite (yellow and magenta); the paramagnetic minerals (blue and green).

Table 2. Hyperfine parameters of the magnetic phases obtained from the MS spectrum of fly ash.

\begin{tabular}{cccccl}
\hline Subspectrum & $\boldsymbol{I}, \boldsymbol{\%}$ & $\boldsymbol{\delta}, \mathbf{~ m m} / \mathbf{s}$ & $\mathbf{2} \boldsymbol{\varepsilon}, \mathbf{~ m m} / \mathbf{s}$ & $\boldsymbol{H}_{\boldsymbol{n}}, \mathbf{k O e}$ & Assignment \\
\hline S1 & $3.3 \pm 0.9$ & $0.39 \pm 0.02$ & $-0.09 \pm 0.04$ & $516 \pm 1$ & Hematite \\
S2 & $13.5 \pm 0.9$ & $0.33 \pm 0.01$ & $0.01 \pm 0.01$ & $485 \pm 1$ & Magnetite $\left[\mathrm{Fe}^{3+}\right]^{\text {tetra }}$ \\
S3 & $11.0 \pm 0.7$ & $0.53 \pm 0.01$ & $-0.04 \pm 0.01$ & $459 \pm 2$ & Magnetite $\left[\mathrm{Fe} e^{3+}\right]^{o c t a}$ \\
S4 & $5.4 \pm 0.4$ & $0.58 \pm 0.01$ & $0.09 \pm 0.01$ & $429 \pm 2$ & Magnetite $\left[\mathrm{Fe} e^{2+}\right]^{o c t a}$ \\
S5 & $2.4 \pm 0.3$ & $0.66 \pm 0.02$ & $0.28 \pm 0.04$ & $384 \pm 2$ & Magnetite $\left[\mathrm{Fe}^{2+}\right]^{o c t a}$ \\
\hline
\end{tabular}

I: relative spectral area; $\delta$ : isomer shift relative to metallic iron at $300 \mathrm{~K} ; \varepsilon$ : quadrupole shift; $H_{n}$ : hyperfine field at ${ }^{57} \mathrm{Fe}$ nuclei at maximum of the distribution.

The paramagnetic part of the fly ash spectrum was processed by two distributions of the quadrupole displacement, separately for $\mathrm{Fe}^{2+}$ and $\mathrm{Fe}^{3+}$ ions with the relative spectral areas $34.0 \pm 0.9 \%$ and $30.4 \pm 0.9 \%$, respectively.

Figure 3 shows the $X$-ray diffraction pattern of fly ash. The reflections of quartz $\mathrm{SiO}_{2}$ $(\mathrm{Q})$, magnetite $\mathrm{Fe}_{3} \mathrm{O}_{4}(\mathrm{Mg})$, hematite $\alpha-\mathrm{Fe}_{2} \mathrm{O}_{3}(\mathrm{Hm})$, mullite $\mathrm{Al}_{6} \mathrm{Si}_{2} \mathrm{O}_{13}(\mathrm{Mu})$, and hercynite $\mathrm{FeAl}_{2} \mathrm{O}_{4}(\mathrm{He})$ are observed against the background of a halo, indicating the presence of the amorphous phase.

Figure 4 shows the Mössbauer spectra of the samples of fly ash narrow fractions produced after granulometric separation. It is easy to see that a decrease in the magnetic component is observed with the growth of the granule size. In a sample with a particle size of more than $100 \mu \mathrm{m}$, the content of ferroxides is minimal; the paramagnetic components are predominant. The distribution of iron over magnetically ordered and paramagnetic phases in the Mössbauer spectra of fly ash narrow fractions is presented in Table 3. 


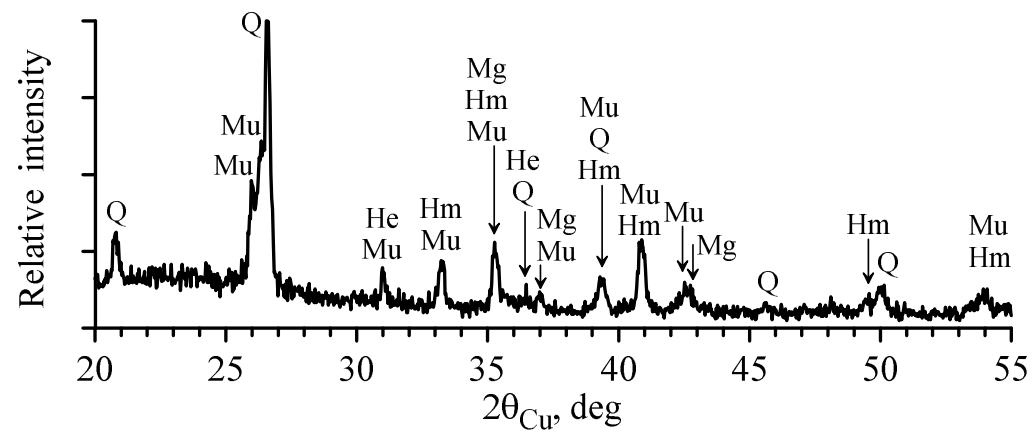

Figure 3. X-ray diffraction patterns of the fly ash sample.

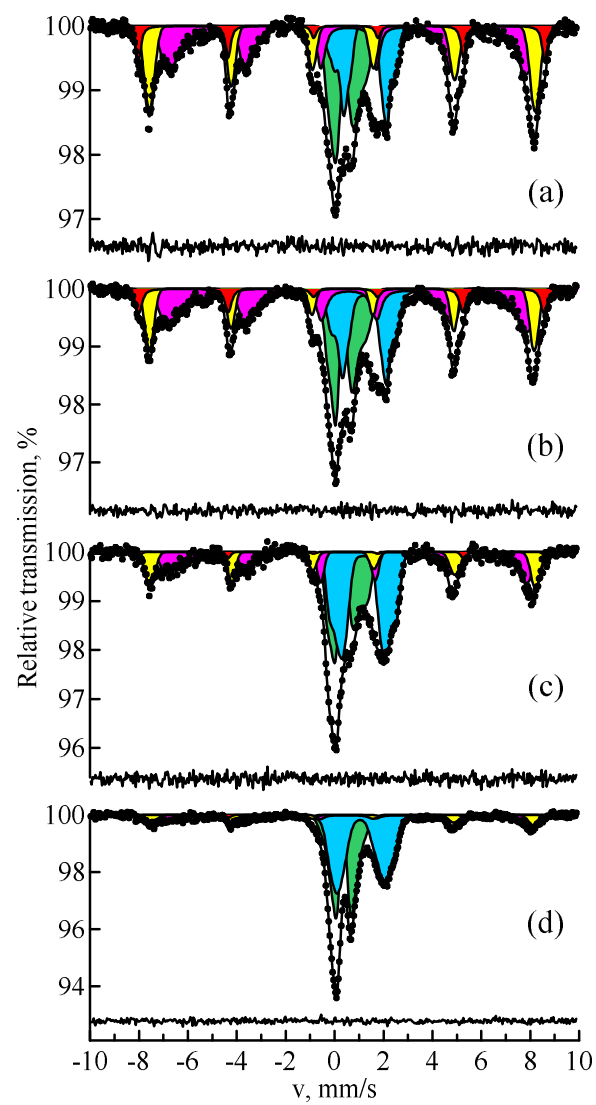

Figure 4. MS spectra of ${ }^{57} \mathrm{Fe}$ nuclei of the samples of fly ash narrow fractions with a particle size of less than $25 \mu \mathrm{m}(\mathbf{a}), 25-40 \mu \mathrm{m}(\mathbf{b}), 40-100 \mu \mathrm{m}(\mathbf{c})$, and more than $100 \mu \mathrm{m}(\mathbf{d})$ : hematite (red); magnetite (yellow and magenta); paramagnetic minerals (blue and green).

Table 3. Distribution of iron over magnetically ordered $\left(I_{m}\right)$ and paramagnetic $\left(I_{p m}\right)$ phases in narrow fractions of fly ash.

\begin{tabular}{ccc}
\hline Particle Size, $\boldsymbol{\mu m}$ & $\boldsymbol{I}_{\boldsymbol{m}}, \boldsymbol{\%}$ & $\boldsymbol{I}_{\boldsymbol{p m}}, \boldsymbol{\%}$ \\
\hline$<25$ & $62 \pm 4$ & $38 \pm 2$ \\
$25 \div 40$ & $55 \pm 3$ & $45 \pm 1$ \\
$40 \div 100$ & $37 \pm 2$ & $63 \pm 1$ \\
$>100$ & $19 \pm 1$ & $81 \pm 1$ \\
\hline
\end{tabular}

To study ferrospheres and aluminosilicate microspheres, the fractions separated from fly ash by the granulometric method were subjected to magnetic separation. Figure 5 shows the Mössbauer spectra of the samples of narrow magnetic fractions that resulted from the second stage of magnetic separation. Table 4 shows the Mössbauer parameters of 
the magnetic phases for the spectrum of the sample with particles less than $25 \mu \mathrm{m}$. Table 5 shows the distribution of iron over magnetically ordered phases versus particle size. It can be seen that iron in ferrospheres is found mainly in the structure of $\mathrm{Fe}_{3} \mathrm{O}_{4} / \gamma-\mathrm{Fe}_{2} \mathrm{O}_{3}$ and $\alpha-\mathrm{Fe}_{2} \mathrm{O}_{3}$. Moreover, the dominant phase is $\mathrm{Fe}_{3} \mathrm{O}_{4}(60-77 \%)$, the amount of which decreases with the growth of the granule size. This is associated with the fact that $\mathrm{Fe}_{3} \mathrm{O}_{4}$ is formed from $\alpha-\mathrm{Fe}_{2} \mathrm{O}_{3}$ at temperatures above $1400{ }^{\circ} \mathrm{C}$. Probably, the equimolar oxidation of $\mathrm{Fe}_{3} \mathrm{O}_{4}$ to $\gamma-\mathrm{Fe}_{2} \mathrm{O}_{3}$ occurs upon cooling from high temperatures. Moreover, this process occurs in smaller granules that have greater contact with the oxidizing atmosphere in the heating unit.

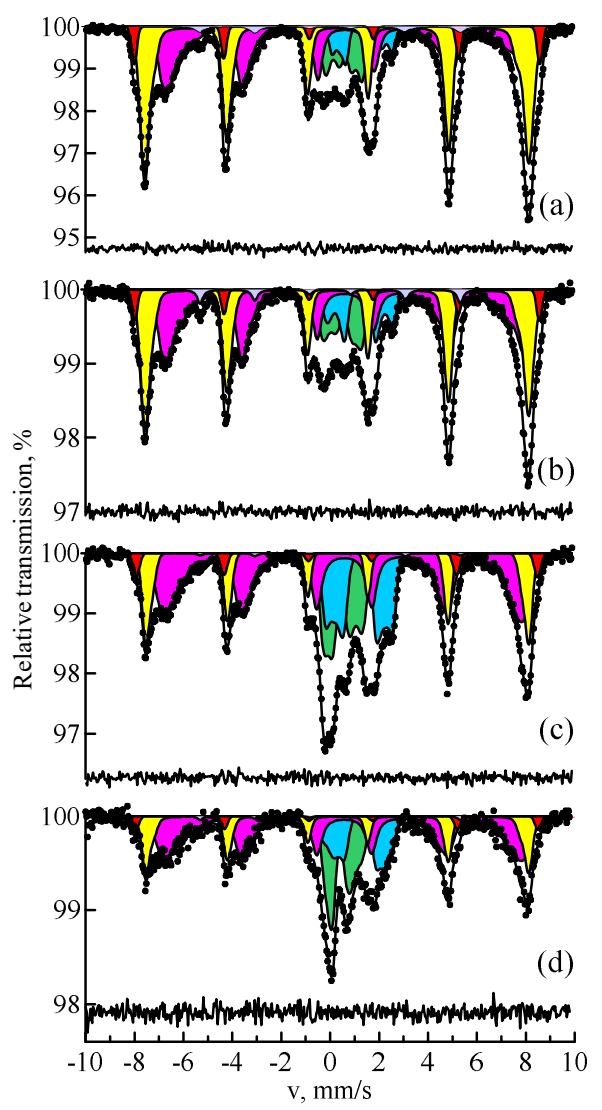

Figure 5. MS spectra of ${ }^{57} \mathrm{Fe}$ nuclei of the samples of narrow magnetic fractions of fly ash with a particle size of less than $25 \mu \mathrm{m}(\mathbf{a}), 25-40 \mu \mathrm{m}(\mathbf{b}), 40-100 \mu \mathrm{m}(\mathbf{c})$, and more than $100 \mu \mathrm{m}(\mathbf{d})$ : hematite (red); magnetite (yellow and magenta); the paramagnetic minerals (blue and green).

Table 4. Hyperfine parameters of the magnetic phases obtained from the MS spectrum of the sample with the particles less than $25 \mu \mathrm{m}$.

\begin{tabular}{cccccl}
\hline Subspectrum & $\boldsymbol{I}, \boldsymbol{\%}$ & $\boldsymbol{\delta}, \mathbf{~} \mathbf{m} / \mathbf{s}$ & $\mathbf{2} \boldsymbol{\varepsilon} \mathbf{~} \mathbf{m m} / \mathbf{s}$ & $\boldsymbol{H}_{\boldsymbol{n}}, \mathbf{k O e}$ & Assignment \\
\hline S1 & $4.9 \pm 0.8$ & $0.37 \pm 0.01$ & $-0.09 \pm 0.01$ & $514 \pm 2$ & Hematite \\
S2 & $41.5 \pm 0.9$ & $0.29 \pm 0.01$ & $-0.04 \pm 0.01$ & $487 \pm 2$ & Magnetite $\left[F e^{3+}\right]^{\text {tetra }}$ \\
S3 & $14.2 \pm 0.9$ & $0.68 \pm 0.01$ & $0.01 \pm 0.01$ & $463 \pm 2$ & Magnetite $\left[F e^{3+}\right]^{\text {octa }}$ \\
S4 & $15.1 \pm 0.9$ & $0.65 \pm 0.01$ & $0.02 \pm 0.01$ & $436 \pm 3$ & Magnetite $\left[F e^{2+}\right]^{\text {octa }}$ \\
S5 & $6.4 \pm 0.7$ & $0.59 \pm 0.02$ & $0.05 \pm 0.01$ & $399 \pm 3$ & Magnetite $\left[F e^{2+}\right]^{\text {octa }}$ \\
S6 & $2.1 \pm 0.6$ & $0.00 \pm 0.03$ & $0.09 \pm 0.01$ & $329 \pm 2$ & $\alpha$-Fe \\
\hline
\end{tabular}

In addition to the magnetically ordered state, the samples contain $\mathrm{Fe}^{2+}$ and $\mathrm{Fe}^{3+}$ ions in a paramagnetic structure. In accordance with $[4,7,12]$, mullite crystals are precipitated on the surface of shells and inside the globules of magnetic microspheres with a high aluminum content. It follows from [6] that the paramagnetic part of the spectrum of magnetic 
microspheres also contains mullite. In addition, there is hercynite and aluminosilicate glass with the admixture of iron.

Table 5. Distribution of iron over magnetically ordered phases in the magnetic narrow fractions of fly ash.

\begin{tabular}{cccc}
\hline Particle Size, $\mu \mathrm{m}$ & $\alpha-\mathrm{Fe}, \boldsymbol{\%}$ & $\alpha-\mathrm{Fe}_{2} \mathrm{O}_{3}, \%$ & $\mathrm{Fe}_{3} \mathrm{O}_{4} / \gamma-\mathrm{Fe}_{2} \mathrm{O}_{3}, \%$ \\
\hline$<25$ & $2 \pm 1$ & $5 \pm 1$ & $77 \pm 3$ \\
$25-40$ & $3 \pm 1$ & $4 \pm 1$ & $74 \pm 3$ \\
$40-100$ & $1 \pm 1$ & $4 \pm 1$ & $60 \pm 2$ \\
$>100$ & $1 \pm 1$ & $3 \pm 1$ & $61 \pm 5$ \\
\hline
\end{tabular}

Natural metallic iron was not detected in the Mössbauer spectrum of the fly ash sample before magnetic separation. Apparently, this is caused by the very low content of $\alpha$-Fe for its identification in such a complex spectrum of fly ash. This became possible in the spectra of the separated magnetic samples. In the spectra of the samples of fly ash narrow fractions, in addition to $\alpha-\mathrm{Fe}_{2} \mathrm{O}_{3}$ and $\mathrm{Fe}_{3} \mathrm{O}_{4}$, there is a small amount of $\alpha$-Fe. Iron reduction is in principle possible when the particles pass through a flare zone with a reducing atmosphere. In the combustion unit, both oxidizing and reducing atmosphere are formed, depending on the amount of oxide and carbon dioxide in the gas mixture. If the $\mathrm{CO}_{2} / \mathrm{CO}$ ratio is greater than a certain value, then iron will be reduced to metal, which is followed by encapsulation into aluminosilicate or ferrosphere globules.

One more interesting experimental fact draws attention. Table 6 shows the ratio of $[\mathrm{Fe}]^{\text {tetra }} /[\mathrm{Fe}]^{\text {octa }}$ positions occupancy in $\mathrm{Fe}_{3} \mathrm{O}_{4}$ in the spectra of the narrow magnetic fraction samples. It can be seen that with the growth of particle size above $40 \mu \mathrm{m}$, the ratio $[\mathrm{Fe}]^{\text {tetra }} /[\mathrm{Fe}]^{\text {octa }}$ decreases; the structure of magnetite tends to the stoichiometric composition, which can be explained by the fact that fine particles can contain $\mathrm{Fe}_{3} \mathrm{O}_{4} / \gamma-\mathrm{Fe}_{2} \mathrm{O}_{3}$ and isomorphic impurities in the octahedral position of magnetite. Small particles will have a higher oxidation rate due to greater contact with the gaseous oxidizing atmosphere, which is consistent with [7].

Table 6. The ratio of the positions occupancy in $\mathrm{Fe}_{3} \mathrm{O}_{4}$.

\begin{tabular}{cc}
\hline Particle Size, $\mu \mathrm{m}$ & {$[\mathrm{Fe}]^{\text {tetra }} /[\mathrm{Fe}]^{\text {octa }}$} \\
\hline$<25$ & $1.16 \pm 0.08$ \\
$25-40$ & $0.88 \pm 0.06$ \\
$40-100$ & $0.46 \pm 0.04$ \\
$>100$ & $0.47 \pm 0.09$ \\
\hline
\end{tabular}

In addition to the magnetically ordered phases, the narrow magnetic fractions of fly ash contain a paramagnetic impurity mechanically bound to the magnetic part, and its content increases with the growth of the particle size.

Figure 6 shows the Mössbauer spectra of the samples of narrow non-magnetic fractions. Taking into account the similarity of the spectra of the samples with the particles of different sizes, Table 7 shows the Mössbauer parameters only for the spectrum of the sample with the particles less than $25 \mu \mathrm{m}$. The MS spectrum was processed by model decoding using seven doublets. D1-D3 doublets are caused by $\mathrm{Fe}^{2+}$ ions in the tetrahedral environment and $\mathrm{Fe}^{2+}, \mathrm{Fe}^{3+}$ ions in the octahedral environment in the hercynite crystal lattice. The $D 4-D 6$ doublets characterize $\mathrm{Fe}^{3+}$ ions in the octahedral environment and $\mathrm{Fe}^{3+}, \mathrm{Fe}^{2+}$ ions in the tetrahedral environment in the mullite crystal lattice. $D 7$ doublet refers to $\mathrm{Fe}^{2+}$ in the octahedral environment of silicate glass [6,19]. Table 8 shows the phase composition of the narrow non-magnetic fractions. 


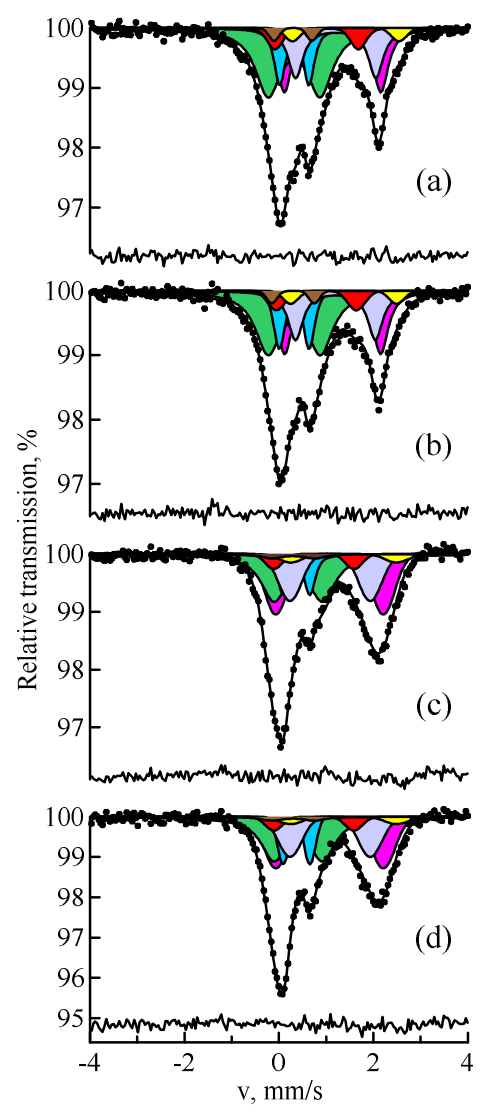

Figure 6. MS spectra of ${ }^{57} \mathrm{Fe}$ nuclei of the samples of narrow non-magnetic fractions of fly ash with a particle size of less than $25 \mu \mathrm{m}(\mathbf{a}), 25-40 \mu \mathrm{m}(\mathbf{b}), 40-100 \mu \mathrm{m}(\mathbf{c})$, and more than $100 \mu \mathrm{m}(\mathbf{d})$ : mullite (green, blue, and red); hercynite (powder blue, yellow, and brown); silicate (magenta).

Table 7. Hyperfine parameters of the non-magnetic fraction obtained from the MS spectrum of the sample with the particles less than $25 \mu \mathrm{m}$.

\begin{tabular}{|c|c|c|c|c|}
\hline Subspectrum & $I, \%$ & $\delta, \mathrm{mm} / \mathrm{s}$ & $\Delta, \mathrm{mm} / \mathrm{s}$ & Assignment \\
\hline D1 & $17.0 \pm 0.3$ & $1.20 \pm 0.03$ & $1.70 \pm 0.06$ & Hercynite $\left[\mathrm{Fe}^{2+}\right]^{\text {tetra }}$ \\
\hline D2 & $3.1 \pm 0.1$ & $1.41 \pm 0.09$ & $2.26 \pm 0.09$ & Hercynite $\left[\mathrm{Fe}^{2+}\right]^{o c t a}$ \\
\hline D3 & $2.0 \pm 0.1$ & $0.30 \pm 0.09$ & $0.80 \pm 0.09$ & Hercynite $\left[\mathrm{Fe}^{3+}\right]^{o c t a}$ \\
\hline$D 4$ & $37.3 \pm 0.9$ & $0.32 \pm 0.02$ & $1.14 \pm 0.06$ & Mullite $\left[F e^{3+}\right]^{o c t a}$ \\
\hline D5 & $13.1 \pm 0.2$ & $0.33 \pm 0.03$ & $0.62 \pm 0.04$ & Mullite $\left[F e^{3+}\right]^{\text {tetra }}$ \\
\hline$D 6$ & $5.6 \pm 0.1$ & $0.80 \pm 0.09$ & $1.76 \pm 0.09$ & Mullite $\left[F e^{2+}\right]^{\text {tetra }}$ \\
\hline D7 & $21.9 \pm 0.4$ & $1.14 \pm 0.02$ & $2.04 \pm 0.02$ & Silicate $\left[\mathrm{Fe}^{2+}\right]^{o c t a}$ \\
\hline
\end{tabular}

$\Delta:$ quadrupole splitting.

Table 8. Phase composition (\%) of narrow non-magnetic fractions.

\begin{tabular}{cccc}
\hline Particle Size, $\boldsymbol{\mu m}$ & Hercynite & Mullite & Silicates \\
\hline$<25$ & $22 \pm 1$ & $56 \pm 1$ & $22 \pm 1$ \\
$25-40$ & $23 \pm 1$ & $54 \pm 1$ & $23 \pm 1$ \\
$40-100$ & $27 \pm 1$ & $47 \pm 2$ & $26 \pm 1$ \\
$>100$ & $26 \pm 1$ & $49 \pm 1$ & $25 \pm 1$ \\
\hline
\end{tabular}

The paramagnetic impurity mechanically bound to the magnetic part of the separated samples (see Figure 5) is identical in quality to the non-magnetic fraction of fly ash, the main components of which are mullite, hercynite, and silicate glass.

Figure 7 shows the SEM images of magnetic (a) and non-magnetic (b) fly ash fractions with particle size less than $25 \mu \mathrm{m}$. Tables 9 and 10 show the elemental composition of the 
particles marked on the SEM images. Figure 7a shows a cluster of nearly perfect spherical globules of various sizes. As the particle size decreases, their spheroidality improves. There are globules with both smooth and embossed surfaces. The iron content in them varies from 37.43 to $85.26 \mathrm{wt} \%$, the content of aluminum is from 1.76 to $14 \mathrm{wt} \%$, and the content of silicon is from 3.52 to $22.53 \mathrm{wt} \%$. It can be seen from Table 6 that in the magnetic narrow fractions of fly ash with the granule size less than $25 \mu \mathrm{m}$, the ratio of positions occupancy $[\mathrm{Fe}]^{\text {tetra }} /[\mathrm{Fe}]^{\text {octa }}=1.16 \pm 0.08$. Such a significant violation of stoichiometry in magnetite cannot be provided by isomorphic impurities. The content of magnesium and calcium in the magnetic fractions with granule size less than $25 \mu \mathrm{m}$ is higher than in the magnetic fractions of granules of larger sizes. In addition, the content of magnesium in the magnetic fraction is significantly higher than in the non-magnetic fraction. Apparently, these elements are precursors in the formation of magnesium ferrites, which can contribute to the Mössbauer spectrum of the magnetic fraction of the finely dispersed granules of fly ash. Particles of the non-magnetic fraction are mostly of indefinite shape (Figure $7 \mathrm{~b}$ ), silicon is the predominant element in them-from 53.84 to $66.67 \mathrm{wt} \%$.

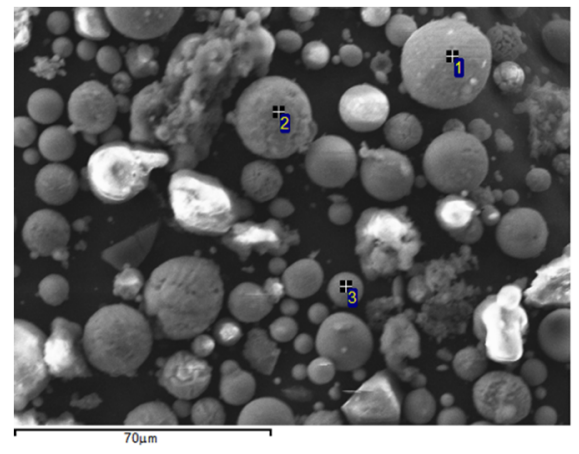

(a)

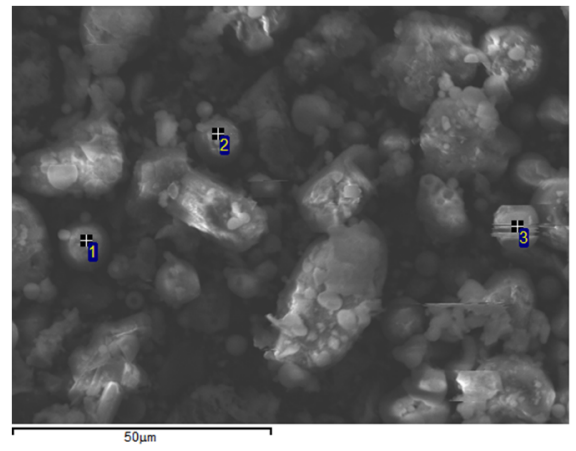

(b)

Figure 7. SEM images of magnetic (a) and non-magnetic (b) narrow fractions of fly ash with a particle size less than $25 \mu \mathrm{m}$.

Table 9. Elemental composition (wt \%) of narrow magnetic fraction of fly ash with a particle size less than $25 \mu \mathrm{m}$.

\begin{tabular}{crrrrrrrrr}
\hline Particle & $\mathbf{M g O}$ & $\mathrm{Al}_{\mathbf{2}} \mathbf{O}_{\mathbf{3}}$ & $\mathrm{SiO}_{\mathbf{2}}$ & $\mathbf{P}_{\mathbf{2}} \mathbf{O}_{\mathbf{5}}$ & $\mathbf{S O}_{3}$ & $\mathbf{C a O}$ & $\mathrm{TiO}_{2}$ & $\mathbf{M n O}$ & $\mathrm{Fe}_{2} \mathbf{O}_{\mathbf{3}}$ \\
\hline 1 & 5.01 & 1.76 & 3.52 & 0.67 & 0.80 & 1.06 & 0.00 & 1.92 & 85.26 \\
2 & 3.08 & 3.35 & 19.68 & 1.67 & 0.12 & 2.48 & 0.26 & 1.80 & 67.55 \\
3 & 5.82 & 14.00 & 22.53 & 5.83 & 0.00 & 13.21 & 0.20 & 0.99 & 37.43 \\
\hline
\end{tabular}

Table 10. Elemental composition (wt \%) of narrow non-magnetic fraction of fly ash with a particle size less than $25 \mu \mathrm{m}$.

\begin{tabular}{crrrrrrrrrrrrr}
\hline Particle & $\mathbf{N a}_{\mathbf{2}} \mathbf{O}$ & $\mathbf{M g O}$ & $\mathbf{A l}_{\mathbf{2}} \mathbf{O}_{\mathbf{3}}$ & $\mathbf{S i O}_{\mathbf{2}}$ & $\mathbf{P}_{\mathbf{2}} \mathbf{O}_{\mathbf{5}}$ & $\mathbf{S O}_{\mathbf{3}}$ & $\mathbf{K}_{\mathbf{2}} \mathbf{O}$ & $\mathbf{C a O}$ & $\mathrm{TiO}_{2}$ & $\mathbf{M n O}$ & $\mathbf{F e}_{\mathbf{2}} \mathbf{O}_{\mathbf{3}}$ & $\mathrm{Cu}_{\mathbf{2}} \mathbf{O}$ & $\mathrm{ZnO}$ \\
\hline 1 & 0.96 & 1.58 & 13.47 & 61.65 & & 1.08 & 0.83 & 4.68 & 0.29 & 0.29 & 11.71 & 0.41 & 0.49 \\
2 & 0.65 & 0.82 & 19.99 & 66.67 & 0.28 & 0.26 & 0.86 & 2.68 & 0.67 & 0.42 & 6.29 & 0.33 & \\
3 & 0.74 & 0.58 & 28.41 & 53.84 & 0.94 & & 0.79 & 1.62 & 1.22 & 0.31 & 11.25 & 0.25 & \\
\hline
\end{tabular}

Thus, the study of granular narrow fractions by the SEM method made it possible to confirm, and in some cases to clarify, the conclusions made according to the results of Mössbauer studies.

\section{Conclusions}

The studies of the narrow fractions of fly ash resulted from combustion of Ekibastuz coal have been completed. Two groups of samples of the magnetic and non-magnetic type with the grain size less than $25 \mu \mathrm{m}, 25-40 \mu \mathrm{m}, 40-100 \mu \mathrm{m}$, and more than $100 \mu \mathrm{m}$ were identified by granulometric and magnetic separation. Several regularities have been 
revealed related to the size of granules and the phase composition of the narrow fractions of fly ash.

According to MS data, after granulometric separation, a decrease in the magnetically ordered contribution was established with the growth of the particle size. In the sample with a particle size of more than $100 \mu \mathrm{m}$, the content of ferroxides is minimal; the minerals mullite and hercynite are predominant. Labeled magnetic particles less than $25 \mu \mathrm{m}$ in size can be used as indicators in those fields of ferrospheres application, where materials with strong magnetic properties are required.

After magnetic separation, iron in ferrospheres is found mainly in the structure of $\mathrm{Fe}_{3} \mathrm{O}_{4} / \gamma-\mathrm{Fe}_{2} \mathrm{O}_{3}$ and $\alpha-\mathrm{Fe}_{2} \mathrm{O}_{3}$. Moreover, the dominant phase is $\mathrm{Fe}_{3} \mathrm{O}_{4}(60-77 \%)$, the amount of which decreases with the growth of the granules size. It was found that with the growth of the particle size, the ratio of the positions occupancy $[\mathrm{Fe}]^{\mathrm{tetra}} /[\mathrm{Fe}]^{0 \mathrm{cta} a}$ in $\mathrm{Fe}_{3} \mathrm{O}_{4}$ approaches 0.5; the structure of magnetite tends to the stoichiometric composition. This is caused by the fact that $\mathrm{Fe}_{3} \mathrm{O}_{4}$ is formed from $\alpha-\mathrm{Fe}_{2} \mathrm{O}_{3}$ at the temperatures above $1400{ }^{\circ} \mathrm{C}$. Probably, equimolar oxidation of $\mathrm{Fe}_{3} \mathrm{O}_{4}$ to $\gamma-\mathrm{Fe}_{2} \mathrm{O}_{3}$ occurs upon cooling from high temperatures. Moreover, this process occurs in smaller granules that have greater contact with the oxidizing atmosphere in the heating unit. $\alpha$-Fe was found in the composition of ferrospheres, and a mechanism of its formation was proposed. The paramagnetic impurity, which is mechanically bound to the magnetic part of the separated samples by its qualitative composition, is identical to the non-magnetic fraction of fly ash, the main components of which are mullite, hercynite, and silicate glass. The content of paramagnetic impurity in the magnetic fraction increases with the growth of the particle size.

Author Contributions: Conceptualization, A.S., S.S. and M.V.; methodology, formal analysis and writing-original draft preparation, M.V. and I.M.; investigation and writing-review and editing, A.S., M.V. and I.M.; visualization, I.M.; project administration, A.S. and M.V.; resources, A.S. All authors have read and agreed to the published version of the manuscript.

Funding: This research was funded by Abai Kazakh National Pedagogical University (Order 0404/97 dated 6 April 2021).

Institutional Review Board Statement: Not applicable.

Informed Consent Statement: Not applicable.

Data Availability Statement: The data presented in this study are available on request from the corresponding author.

Acknowledgments: The authors express their gratitude to Vladimir Yaskevich for assistance provided in the experiments.

Conflicts of Interest: The authors declare no conflict of interest.

\section{References}

1. Kizilshtein, L.Y. Traces of coal-fired power industry. Sci. Life 2008, 5, 42-47.

2. Adeeva, L.N.; Borbat, V.F. Heating and power plant ash-The promising raw materials for the industry. Bull. Omsk Univ. 2009, 2, 141-151.

3. Zorya, V.N.; Korovushkinm, V.V.; Permyakov, A.A.; Volynkina, E.P. The research of the mineral composition and crystal structure of iron-containing components of technogenic waste of the metallurgical complex. Izv. Vyss. Uchebnykh Zavedenij Chernaya Metall. 2015, 58, 359-366. [CrossRef]

4. Zyryanov, V.V.; Petrov, S.A.; Matvienko, A.A. Characterization of spinel and magnetospheres of coal fly ashes collected in power plants in the former USSR. Fuel 2011, 90, 486-492. [CrossRef]

5. Samorokov, V.E.; Zelinskaya, E.V. Use of micro-spheres in composite materials. Bull. Irkutsk State Univ. 2012 , 9, $201-205$.

6. Shokanov, A.; Vereshchak, M.; Manakova, I. Mössbauer and X-ray Studies of Phase Composition of Fly Ashes Formed after Combustion of Ekibastuz Coal (Kazakhstan). Metals 2020, 10, 929. [CrossRef]

7. Yang, J.; Zhao, Y.; Zyryanov, V.; Zhang, J.; Zhenga, C. Physical-chemical characteristics and elements enrichment of magnetospheres from coal fly ashes. Fuel 2014, 135, 15-26. [CrossRef]

8. Zyryanov, V.V.; Zyryanov, D.V. Fly Ash-Technogenic Raw Material; IIC Maska: Moscow, Russia, 2009.

9. Vatin, N.I.; Petrosov, D.V.; Kalachev, A.I.; Lahtinen, P. Use of ashes and ash-and-slad wastes in construction. J. Civil Eng. 2011, 22, 16-21. [CrossRef] 
10. Kizilshtein, L.; Dubov, I.; Shpitsgluz, A.; Parada, S. Components of Ashes and Slags of Heat Power Plants; Energoatomizdat: Moscow, Russia, 1995.

11. Putilin, E.I.; Tsvetkov, B.C. Application of Fly Ash and Ash and Slag Mixtures in the Construction of Highways; SoyuzDorNII: Moscow, Russia, 2003.

12. Sharonova, O.M.; Fedorchak, M.A.; Mazurova, E.V. The composition and structure of ferrospheres formed by industrial combustion of Ekibastuz coal. J. Sib. Fed. Univ. Chem. 2017, 10, 175-185. [CrossRef]

13. Anshits, N.N.; Solov'ev, L.A.; Rabchevskii, E.V.; Anshits, A.G.; Bayukov, O.A.; Eremin, E.V. Mössbauer and magnetic investigations of high-iron samples of energy ashes. Phys. Solid State 2010, 52, 1188-1192. [CrossRef]

14. Sharonova, O.M.; Anshits, N.N.; Solovyov, L.A.; Salanov, A.N.; Anshits, A.G. Relationship between composition and structure of globules in narrow fractions of ferrospheres. Fuel 2013, 111, 332-343. [CrossRef]

15. Vereshchagina, T.A.; Anshits, N.N.; Zykova, I.D.; Salanov, A.N.; Tret'yakov, A.A.; Anshits, A.G. Preparation of cenospheres of controlled composition from energy ashes and their properties. Khim. Interes. Ust. Razv. 2001, 9, 379-391.

16. Fomenko, E.V.; Anshits, N.N.; Vasil'eva, N.G.; Rogovenko, E.S.; Mikhaylova, O.A.; Mazurova, E.V.; Solov'ev, L.A.; Anshits, A.G. Composition and structure of the shells of aluminosilicate microspheres in fly ash formed on the combustion of Ekibastuz coal. Solid Fuel Chem. 2016, 50, 238-247. [CrossRef]

17. Fedorchak, M.A.; Sharonova, O.M.; Mazurova, Y.V.; Vereshchagina, T.A.; Anshits, A.G. Magnetic affine sorbents for the isolation of recombinant proteins. Inorg. Mater. Appl. Res. 2016, 7, 233-239. [CrossRef]

18. Harchand, K.S.; Taneja, S.P.; Raj, D.; Sharma, P. Mössbauer studies of coal ash. Fuel Process. Technol. 1989, 21, 19-24. [CrossRef]

19. Hinckley, C.C.; Smith, G.V.; Twardowska, H.; Saporoschenko, M.; Shiley, R.H.; Griffen, R.A. Mossbauer studies of iron in Lurgi gasification ashes and power plant fly and bottom ash. Fuel 1980, 59, 161-165. [CrossRef]

20. Vandenberghe, R.E.; de Resende, V.G.; da Costa, G.M.; De Grave, E. Study of loss-on-ignition anomalies found in ashes from combustion of iron-rich coal. Fuel 2010, 89, 2405-2410. [CrossRef]

21. Goldanskii, V.; Herber, R. Chemical Applications of Mössbauer Spectroscopy; Academic: New York, NY, USA, 1968.

22. Kierlik, P.; Hanc-Kuczkowska, A.; Rachwał, M.; Męczyński, R.; Matuła, I. Application of Mössbauer spectroscopy for identification of iron-containing components in upper silesian topsoil being under industrial anthropopressure. Materials 2020, $13,5206$. [CrossRef] [PubMed]

23. Mehrabi-Kalajahi, S.; Varfolomeev, M.A.; Yuan, C.; Rodionov, N.O.; Zinnatullin, A.L.; Vagizov, F.G.; Osin, Y.N. Oil-Dispersed $\alpha-\mathrm{Fe}_{2} \mathrm{O}_{3}$ Nanoparticles as a catalyst for improving heavy oil oxidation. Energy Fuels 2021, 35, 10498-10511. [CrossRef]

24. Manakova, I.A.; Vereshchak, M.F.; Sergeeva, L.S.; Shokanov, A.K.; Antonyuk, V.I.; Rusakov, V.S.; Kadyrzhanov, K.K. Laws of thermally induced formation of phases in $\alpha$-Fe with a titanium coating upon isochronous annealings. Phys. Met. Metallogr. 2010, 109, 447-460. [CrossRef]

25. Kadyrzhanov, K.K.; Vereshchak, M.F.; Manakova, I.A.; Ozernoy, A.N.; Rusakov, V.S. Structure-phase transformations in the Be-Fe-Be layered system subjected to irradiation and thermal treatment. J. Phys. Chem. Solids 2013, 74, 1078-1085. [CrossRef]

26. Andrianov, V.A.; Bedelbekova, K.A.; Ozernoy, A.N.; Vereshchak, M.F.; Manakova, I.A. Mössbauer studies of ${ }^{57}$ Fe implantation in metal Ta and Mo. Nuclear Instrum. Methods Phys. Res. Sect. B Beam Interact. Mater. Atoms. 2020, 475, 71-76. [CrossRef]

27. Shokanov, A.K.; Vereshchak, M.F.; Manakova, I.A.; Bedelbekova, K.A.; Yaskevich, V.I. Mössbauer Study of Iron Carbides Formed by Thermal Vacuum Deposition Shokanov. Crystallogr. Rep. 2020, 65, 363-366. [CrossRef]

28. Vereshchak, M.F.; Manakova, I.A.; Shokanov, A.K.; Suslov, E.E.; Tleubergenov, Z.K.; Smikhan, Y.A. Scanning conversion electronic Mössbauer spectroscopy of local surface layers of materials. Nuclear Instrum. Methods Phys. Res. Sect. B Beam Interact. Mater. Atoms. 2021, 502, 102-105. [CrossRef]

29. Fisher, G.L.; Chang, D.P.Y.; Brumer, M. Fly ash collected from electrostatic precipitators: Microcrystalline structure and the mystery of the spheres. Science 1976, 192, 553-555. [CrossRef] [PubMed]

30. Matsnev, M.E.; Rusakov, V.S. SpectrRelax: An application for Mössbauer spectra modeling and fitting. AIP Conf. Proc. 2012, 1489, 178-185.

31. Shpirt, M.J.; Clair, V.R.; Persikov, I.Z. Inorganic Components of Solid Fuels; Publishing House Khimija: Moscow, Russia, 1990.

32. Vdovenko, M.I. The Mineral Part of Energy Coals (Physicochemical Research); Nauka: Alma-Ata, Kazakhstan, 1973.

33. Gomes, S.; Francois, M.; Abdelmoula, M.; Refait, P.; Pelissier, C.; Evrard, O. Characterization of magnetite in silico-aluminous fly ash by SEM, TEM, XRD, magnetic susceptibility, and Mossbauer spectroscopy. Cem. Concr. Res. 1999, 29, 1705-1711. [CrossRef] 